\title{
Simulation of Grain Quantity, Fan and Solar Collector Sizes for an Experimental Forced Convection Grain Dryer
}

\section{Booker Osodo ${ }^{\rtimes}$ \\ Daudi Nyaanga ${ }^{2}$ Jeremiah Kiplagat ${ }^{3}$}

'Lecturer, Department of Industrial and Energy Engineering, Egerton University, Kenya, Email:bookerosodo@yahoo.com Tel:0722902010

'Associate Professor, Department of Agricultural Engineering, Egerton University, Kenya. Email:dmnyaanga@gmail.com Tel:0721285231

Director, Institute of Energy Research, Kenya Power, Nairobi, Kenya.

Email: Jeremy.kiplagat@gmail.com Tel:0702476094

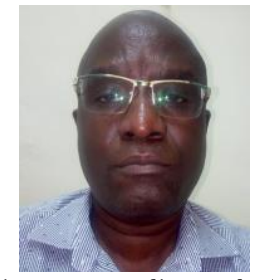

Corresponding Author)

\begin{abstract}
Forced convection grain dryers are more efficient and achieve greater drying rates than natural convection dryers. However, it is necessary to dry an appropriate grain layer thickness in such a dryer for the drying process to occur efficiently and at an appropriate rate. A well sized fan is also essential if the drying process is to proceed effectively. An oversize fan will be unnecessarily expensive to buy and operate due to high fan power, while an undersized one will not be able to supply adequate air flow. The solar collector must be properly sized if it is to heat the air to the required temperature. All these factors need to be addressed during the design of a grain dryer. Lengthy and expensive trial and error processes can be avoided by applying simulation in the design process. This study developed an experimental grain dryer, addressing the above mentioned issues in the process. Simulation of air flow within an initial model of the dryer was done and the results used to size the fan and drying cabinet. The solar collector was also sized. The experimental grain dryer developed consisted of a drying cabinet of dimensions $0.5 \mathrm{~m} \times 0.5 \mathrm{~m}$ $\mathrm{x} 1.0 \mathrm{~m}$ and was equipped with a $0.039 \mathrm{~kW}$ centrifugal fan. The solar collector area was of dimensions $1.2 \mathrm{~m} \times 1.8 \mathrm{~m}$.
\end{abstract}

Keywords: Simulation, Forced convection dryer, Dryer sizing, Fan, Drying cabinet, Solar collector.

Citation | Booker Osodo; Daudi Nyaanga; Jeremiah Kiplagat (2019). Simulation of Grain Quantity, Fan and Solar Collector Sizes for an Experimental Forced Convection Grain Dryer. Agriculture and Food Sciences Research, 6(1): 98-108.

History:

Received: 28 February 2019

Revised: 27 March 2019

Accepted: 1 May 2019

Published: 4 July 2019

Licensed: This work is licensed under a Creative Commons

Attribution 3.0 License (oc) I

Publisher: Asian Online Journal Publishing Group
Contribution/Acknowledgement: All authors contributed to the conception and design of the study.

Funding: This study received no specific financial support.

Competing Interests: The authors declare that they have no conflict of interests.

Transparency: The authors confirm that the manuscipt is an honest, Transparency: The authors confirm that the manuscript is an honest,
accurate, and transparent account of the study was reported; that no vital features of the study have been omitted; and that any discrepancies from the study as planned have been explained.

Ethical: This study follows all ethical practices during writing.

\section{Contents}

1. Introduction

2. Materials and Methods

References. 


\section{Contribution of this paper to the literature}

This article demonstrates that it is possible to use simulation in sizing the various components of a solar dryer. This will result in savings in time and resources which usually results from the normal design process which involves design, fabrication and testing before a prototype is eventually made.

\section{Introduction}

A large proportion of food product is often lost between harvesting and consumption. Adebayo, et al. [1] stated that loss of crop occurs in the field (15\%), during harvesting (13-20\%), as well as during processing and storage (15-25\%). Post-harvest loss of crop may be attributed to different causes. Pests, such as large grain borer account for $10-20 \%$ loss, while $5-10 \%$ of the losses may be attributed to poor storage facilities. Diseases, on the other hand, contribute to $5 \%$ of post-harvest crop loss [2]. The problem of post-harvest food loss is particularly significant in developing countries, where food losses are estimated to be of the order of $40 \%$, though this can rise to be as high as $80 \%$ under very adverse conditions [3]. For example, incidences of post-harvest product loss in Kenya have been estimated at 30\%, and can rise to be as high as $100 \%$ with the advent of afflotoxin [4]. Postharvest loss of maize in Kenya in 2007 was $21.1 \%$ [5]. One reason for loss of grain after harvesting is spoilage resulting from high moisture content. Moist and partly moist crop is prone to fungus infection, which renders it unusable. High moisture content also encourages loss due to attacks by insects, pests and increased respiration. Drying of grain is therefore necessary to avoid loss between harvesting and consumption Tiwari [6]; Twidell and Weir [7]. Barawal and Tiwari [8] reported that drying of crop helps to achieve better product quality, longer safe storage and reduction of post-harvest loss hence ensuring more food is available for the growing world population.

Grain drying may be carried out using different sources of energy. However, solar energy is preferred to other alternative sources of energy such as wind and shale since it is abundant, inexhaustible and non-polluting [9]. In Forced Convection solar drying, a fan is used to force the air through the grain in order to enhance the circulation of the heated air. Such dryers produce greater drying rates and make it easier to control the drying process [10, 11 . The performance of a dryer may also be evaluated based on other criteria such as drying and dryer efficiency, uniformity of drying and quality of final product (extent of cracking and discoloration of grain) as well as total drying time $[12,13]$. Determination of an optimum design that will ensure best ventilation for any particular application is essential to ensure best performance [14].

Although forced convection solar dryers achieve greater drying rates than natural convection dryers, their performance is often not optimal. One reason for this is inadequate distribution of air flow, resulting in inadequate drying air in some sections of the dryer and hence uneven drying of the grain. According to Misha, et al. [15] uneven drying is the consequence of poor air flow distribution in the drying chamber. Product closer to the air inlet is better dried than that further, due to reduced temperature and air velocity. Sometimes, the fan is undersized, leading to insufficient air flow (and velocity), or oversized, leading to excessive energy consumption and in ex treme cases grain being blown upward. Also use of inappropriate grain layer thickness leads poor performance. If the grain layer is too thick, some sections do not dry well as they receive air which is saturated with moisture. If too thin, air exits while still having capacity to remove moisture, leading to low thermal efficiency. Design of dryers that meet these criteria, without use of simulation, would require troublesome development stages, involving trial and error, continued testing and use of prototypes, a process which would be expensive and time consuming. Simulation, which is the imitation or reproduction of the behavior of a system or process [16] is useful in the design process, as it saves on the time and resources that would otherwise be required to obtain optimal performance. In this study, the process of simulation was used to improve on the dryer design and performance. The objective of the study was to simulate the grain quantity, fan and solar collector sizes for an experimental forced convection grain dryer.

\subsection{Solar Thermal Collectors}

A Solar thermal collector serves the purpose of trapping solar radiation which is then used for heating the working fluid. It usually consists of a black surface, the absorber, and a transparent cover. The absorber does not trap all the incident energy from the sun. It incurs losses due to reflection by the encapsulation (cover) or the absorber itself, convection as a result of exchange with the surrounding air, as well as radiation from the hot absorber surface. The efficiency of the collector depends on two factors: the extent to which solar radiation is converted to heat, and the extent of heat losses to the surroundings [17].

For a flat plate collector, solar collector area $A_{c}$ may be determined from Equation 1 used by Dabra, et al. [18] and Aduewa, et al. [19].

$$
A_{c}=\frac{\dot{m}_{a} c_{p a}\left(T_{o}-T_{a}\right)}{I_{c} \eta}
$$

In the equation, $\dot{m}_{a}$ and $c_{\mathrm{pa}}$ represented air mass flow rate and specific heat capacity respectively, while $I_{c}$ and $\eta$ stood for maximum insolation on collector surface and solar collector efficiency, also respectively. $T_{o}$ and $T_{a}$ were used to represent optimum dryer temperature and inlet temperature at ambient.

\subsection{Pressure Drop}

Jia, et al. [20] explain that air flow through packed material may be described using the Ergun Equation 2. According to this equation, pressure $\operatorname{drop}(\Delta P)$, for fluid velocity $\left(u_{0}\right)$ depends on particle diameter $\left(d_{p}\right)$, length of bed $\left(L_{p}\right)$, fluid viscosity $(\mu)$, void space $(\varepsilon)$ and fluid density $(\rho)$. The effect of cross sectional area (due to container diameter) is ignored in this equation.

$$
\frac{\Delta P}{L_{p}}=\frac{150 \mu(1-s)^{2} u_{0}}{s^{s} d_{p}^{2}}+\frac{1.75(1-s) \rho \mu^{2}}{s^{s} d_{p}}
$$

Although there are many channels through packed material, fluid will normally only flow through a few of them, a phenomenon called channeling. This leads to lack of distribution of fluid flow. Another limitation is that of formation of hot spots, which leads to damage to the bed and packing materials [21]. The pressure drop in the 
drying chamber limits the number of trays that may be used. Due to high resistance to air flow through drying product, only a few drying shelves can be used without significantly affecting air movement [22].

\subsection{Fan Sizing}

According to Wilcke and Morey [23] different crops have different airflow requirements for drying, necessitating selection of a fan that will deliver airflows within the recommended range. Greater airflows will require larger fans, leading to increased costs, while smaller ones may result in unacceptable crop quality. Also, the fan must develop sufficient pressure to overcome resistance to airflow. Typical air flow rates range from 0.25-0.51 $\mathrm{m}^{3} / \mathrm{s} . \mathrm{m}^{2}$ of perforated screen area, these flow rates creating relatively low static pressures of $0.249-1.25 \mathrm{kPa}$ in cross flow and mixed-flow dryers. The fan to be used for such a dryer must be of sufficient capacity to overcome this static pressure, being the resistive force the fan works against while trying to push the air through the grain column [24].

Fan power $\left(P_{f}\right)$ may be obtained either from manufacturers' charts or from Equation 3 and 4 as suggested by Wilcke and Morey [23] as well as Maier and Bakker-Arkema [24].

$$
\begin{aligned}
& P_{f}=\frac{\left(V x P_{g}\right)}{63.56 \eta_{f p}} \\
& P_{f}=\frac{\left(V x P_{g}\right)}{3814}
\end{aligned}
$$

( $\dot{\mathrm{V}}$ is air volume flow rate while $\mathrm{P}_{\mathrm{s}}$ represents static pressure)

The equations are similar, although for Equation 4 an impeller efficiency of $60 \%$ has been assumed and incorporated. Weiss and Buchinger [25] stated that fan efficiency ranges between $30 \%$ and $70 \%$, hence the assumption is reasonable to cater for most fans if cost of fan and that of power is the major consideration. In the current study, Equation 4 was adopted to cater for a general situation where efficiency of fan does not have to be used every time.

\section{Materials and Methods \\ 2.1. Research Site}

The study was carried out in Njoro, Nakuru County, Kenya. Njoro is located $18 \mathrm{~km}$ South West of Nakuru town. It lies at an altitude of $1800 \mathrm{~m}$ above sea level, and experiences temperature ranges between $17-22^{\circ} \mathrm{C}$. Nakuru County is a moderate to high solar energy potential area. The amount of available solar energy is season dependent, with the December-February season receiving the highest amount of insolation of $678 \mathrm{kWh} / \mathrm{m}^{2}$. The September-November season receives the least insolation of $602.6 \mathrm{kWh} / \mathrm{m}^{2}$. Harvesting is normally carried out between August and December, depending on the type of grain [26-28].

\subsection{Simulation to Estimate Grain Layer Thickness and Number of Trays}

Simulation was carried out in order to determine the greatest grain layer thickness that would be penetrated by the drying air. This was determined by observing the velocity profile for simulated air flow up different layer thicknesses, with the expectation that air velocity would gradually increase up the layer. According to Ergun's Equation 2 the governing equation in the simulation process, fluid velocity increases as pressure drop increases. The latter increases as fluid moves up the grain layer, hence fluid velocity is expected to vary in a similar manner. Simulation was first carried out of hot air flowing through a single grain layer of $0.1 \mathrm{~m}$ thickness, at an air velocity of $1 \mathrm{~m} / \mathrm{s}$. A parametric sweep was then carried out in order to simulate air flow through various grain layer thicknesses ranging between $0.1 \mathrm{~m}-0.3 \mathrm{~m}$ for air velocities ranging between $1 \mathrm{~m} / \mathrm{s}-5 \mathrm{~m} / \mathrm{s}$. A parametric sweep enables simulation within the specified range of parameter values in one simulation process, without having to do it for discrete values. The purpose of the parametric sweep was to determine the maximum grain layer thickness that would allow the fan to overcome static resistance to airflow.

Once the maximum allowable layer thickness was determined, simulation of air flow up increasing number of grain layers was carried out in order to determine the number of layers the air was able to penetrate. In this case, variation of pressure up the drying cabinet with different grain layer numbers was observed. It was expected that pressure would decrease gradually up the drying cabinet. Any behavior to the contrary would suggest air was not able to penetrate.

The simulation process was carried out in two major stages: creation of the model and simulation of the model. Before simulating air flow up the drying cabinet, a 2-D model of it had to be developed using the software SolidWorks. Once created, the model was imported into the COMSOL MULTI-PHYSICS simulation software and the process of simulation carried out. The simulation process was also in two major stages: pre-processing and post-processing. Figure 1 summarises the model creation process while Figure 2 summarises the preprocessing stage of simulation. 


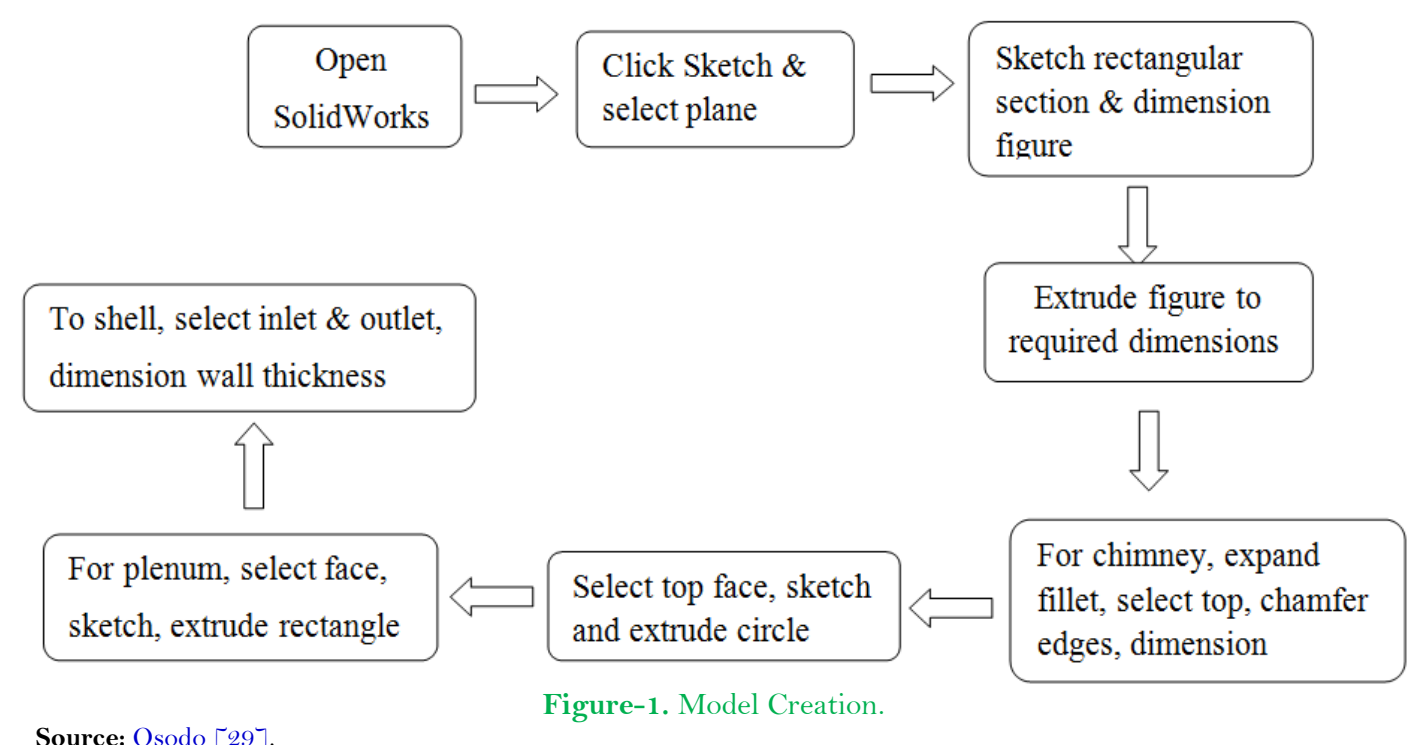

Source: Osodo [29].

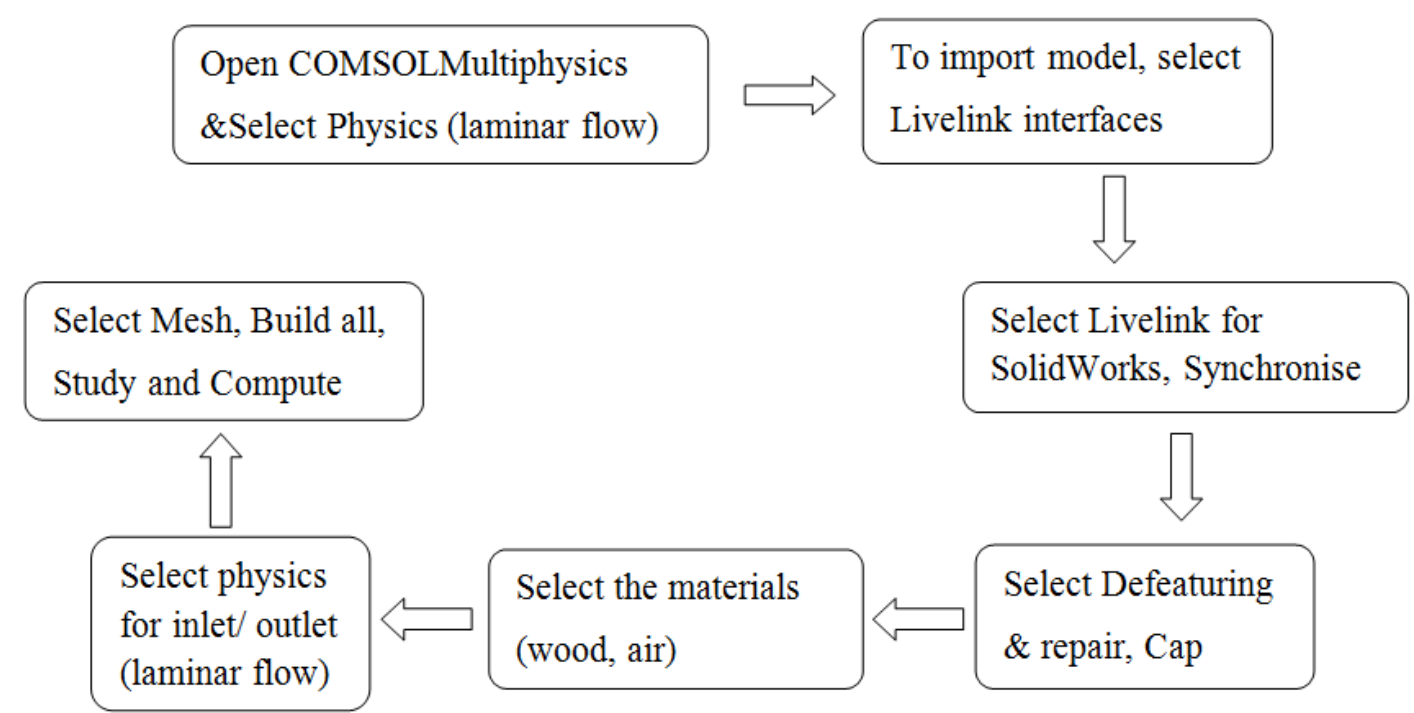

Source: Osodo [29].

Figure-2. Flow Chart of Preprocessing Stage of Simulation.

Once simulation was complete, post-processing, summarized in Figure 3, was carried out to extract the results in various forms as required.

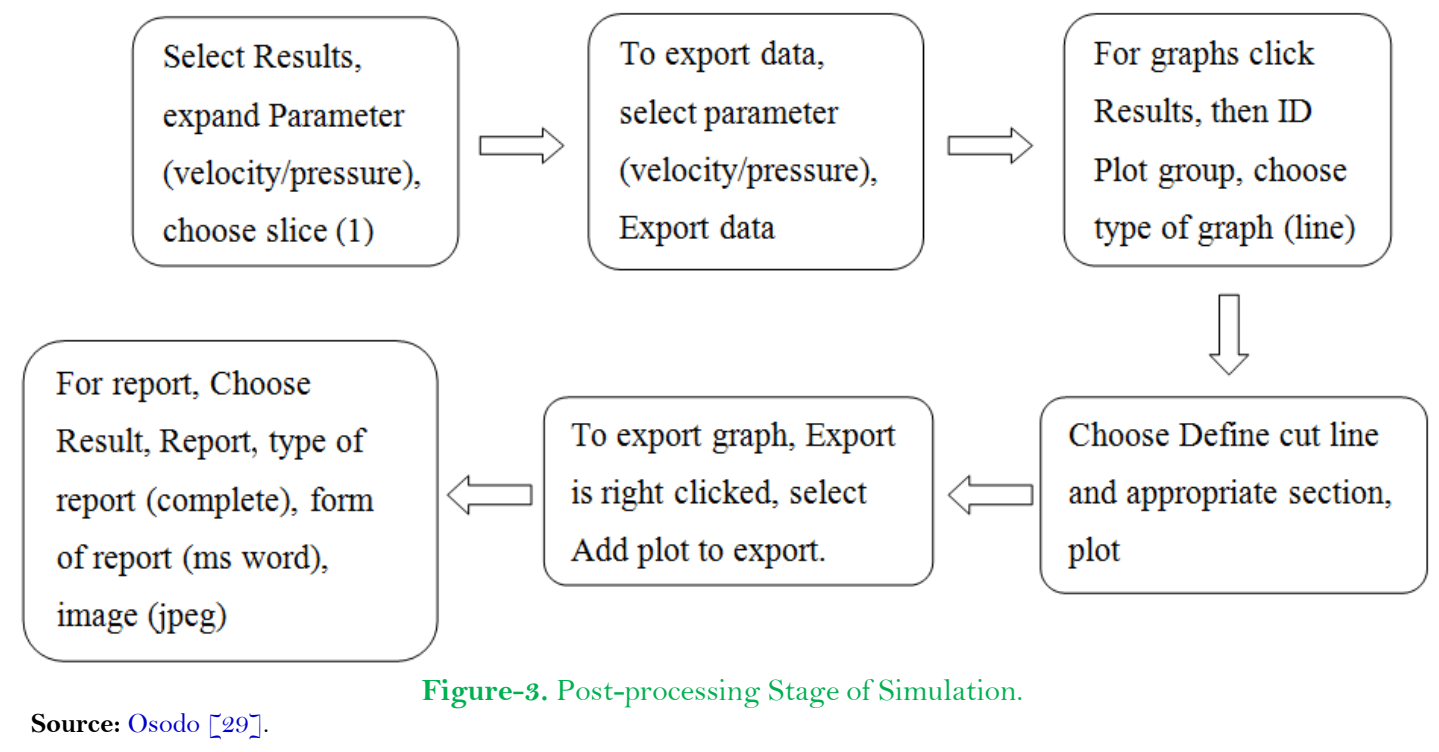

2.3. Sizing of Solar Dryer

2.3.1. Fan Power Determination

Having found the grain layer thickness that would allow penetration by the air, the simulated pressure drop for this layer thickness was taken as being equivalent to the static pressure to be overcome by the suction fan. This static pressure $\left(P_{S}\right)$ as well as the corresponding air flow rate $(\dot{V})$ was applied in Equation 4 to determine the power of the appropriate fan.

\subsubsection{Drying Cabinet and Solar Collector}

i. Drying Cabinet

To determine the cross sectional area of the drying cabinet, a capacity of $18 \mathrm{~kg}$ per tray (a mass that an average family would dry for milling, and also that can be carried comfortably when loading) was assumed. The volume $\left(\mathrm{V}_{\mathrm{gr}}\right)$, of grain per tray was determined using Equation 5 the grain density for maize being $0.76 \mathrm{~g} / \mathrm{cc}$. The cross 
sectional area of the drying cabinet $\mathrm{A}_{\mathrm{cb}}$ was then determined from Equation 6 the value of $t_{g r}$ (maximum grain layer thickness) having been determined as $0.1 \mathrm{~m}$.

$$
\begin{aligned}
& V_{g r}=\frac{m_{g r}}{\rho_{g r}} \\
& A_{c b}=\frac{V_{g r}}{t_{g r}}
\end{aligned}
$$

( $\mathrm{m}_{\mathrm{gr} \text { and }} \rho_{\text {gr }}$ represent mass and density grain respectively)

The height of the drying cabinet was sized to carry two trays, each holding a grain layer thickness equal to $t_{g r}$. The void space between the trays, having a height equal to that of the grain layer, and a plenum chamber, as well as space above the second tray to accommodate the suction fan were also catered for.

\section{ii. Solar Collector}

The solar collector area $\left(\mathrm{A}_{\mathrm{c}}\right)$ was determined using Equation 1. To find the air mass flow rate $\left(\dot{m}_{a}\right)$ Equation 7 and 8 were used. Air velocity was measured at dryer exit, which had a diameter of $0.1 \mathrm{~m}$, using a thermoanemometer, cabinet cross sectional area having been found as shown above.

$$
\begin{aligned}
& Q=A v \\
& \dot{m}=Q \rho_{a}
\end{aligned}
$$

$\left(\mathrm{Q}=\right.$ flow rate in $\mathrm{m}^{3} / \mathrm{s}, \mathrm{A}=$ cross sectional area in $\mathrm{m}^{2}, \mathrm{v}=$ air velocity in $\mathrm{m} / \mathrm{s}, \dot{\mathrm{m}}=$ mass flow rate in $\mathrm{kg} / \mathrm{s}$ and $\rho_{a}=$ density of air in $\mathrm{kg} / \mathrm{m}^{3}$ )

$\mathrm{T}_{\mathrm{i}}$ was taken to be $23^{\circ} \mathrm{C}$ (the ambient temperature measured in research area during drying period) and $\mathrm{T}_{\mathrm{o}}$ as $58^{\circ} \mathrm{C}$ (the maximum temperature to maintain grain quality). A value of $1200 \mathrm{~W} / \mathrm{m}^{2}$ was used as Insolation $\mathrm{I}_{\mathrm{c}}$ (estimated from measurements in the research area), while a solar collector efficiency $(\eta)$ value of $83.28 \%$ was used. This solar collector efficiency was similar to that reported by Aduewa, et al. [19] at insolation of $1199.46 \mathrm{~W} / \mathrm{m}^{2}$.

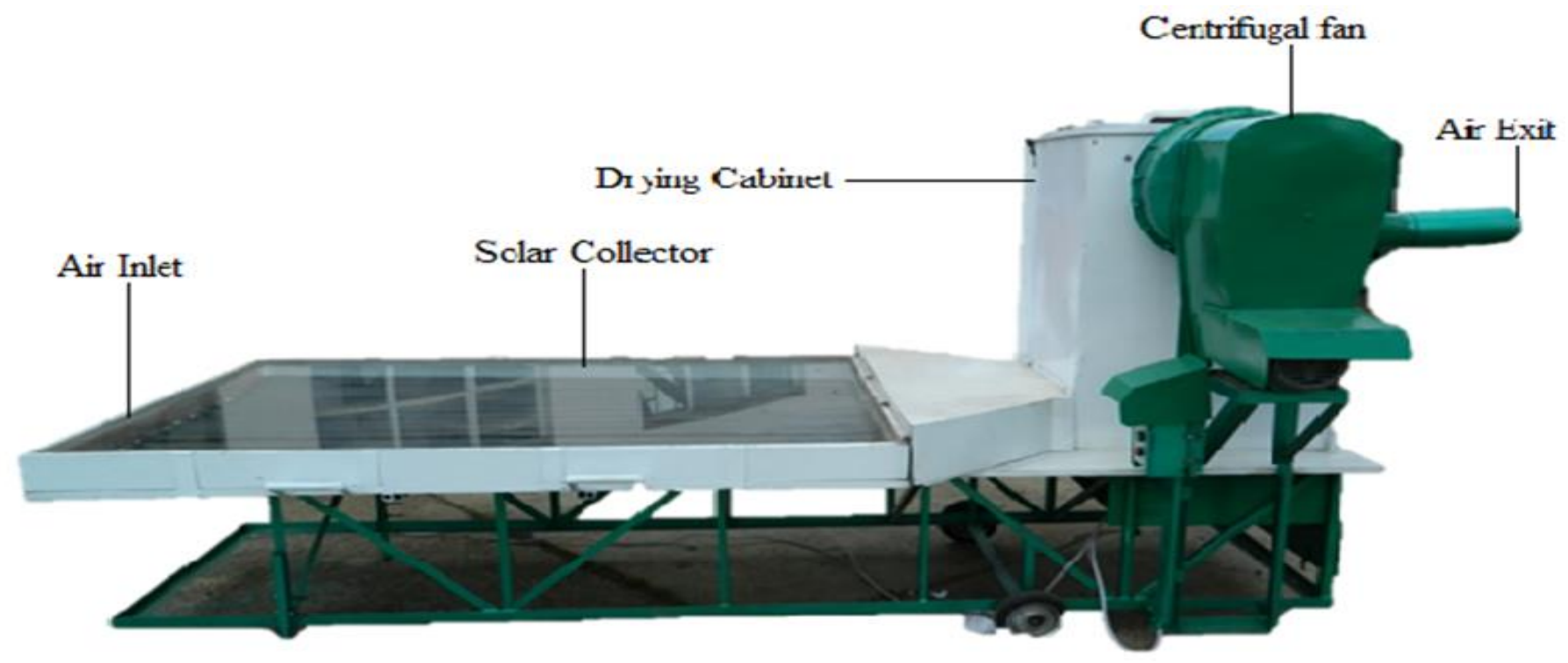

Source: Osodo [29].

Plate-1. Side View of Experimental Solar Grain Dryer.

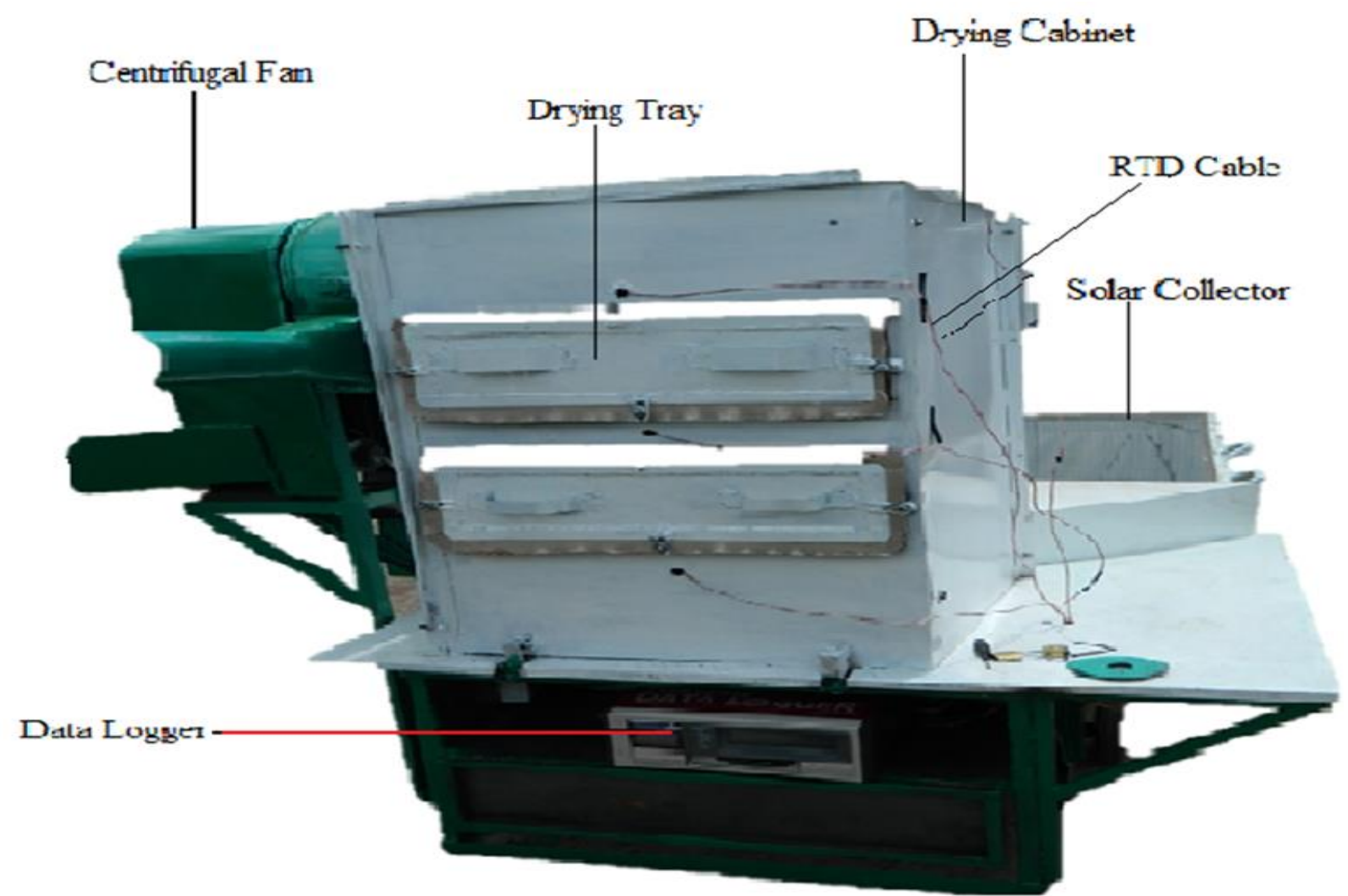

Source: Osodo [29].

Plate-2. Rear View of Experimental Solar Grain Dryer. 


\section{Results and Discussion}

\subsection{Grain Layer Thickness}

In order to select the appropriate grain layer thickness, air flow up different layer thicknesses was simulated. The expectation was that air velocity would increase gradually up the grain layer. Any variation from this expectation would imply an inappropriate layer thickness. Figures $4-7$ show velocity profiles for different layer thicknesses.

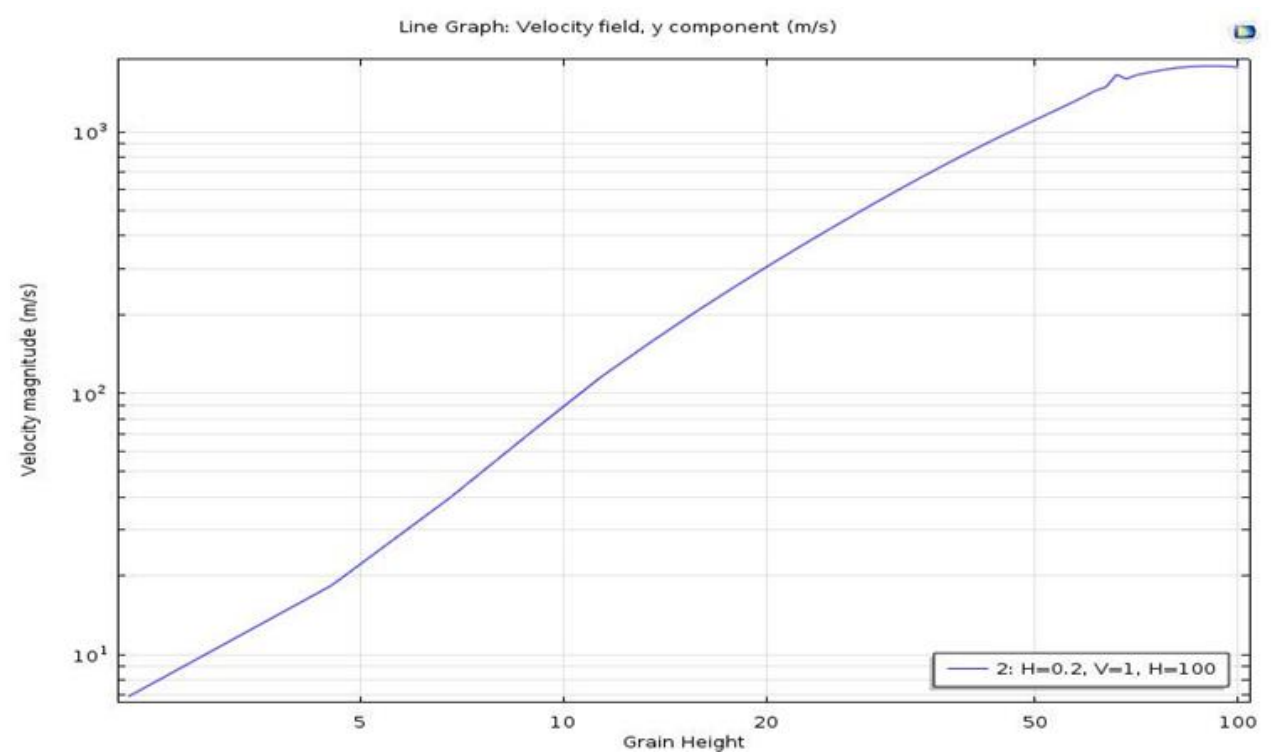

Figure-4. Air Velocity up Single Grain Layer of Height $0.1 \mathrm{~m} \&$ inlet Velocity $1 \mathrm{~m} / \mathrm{s}$. Source: Osodo [29].

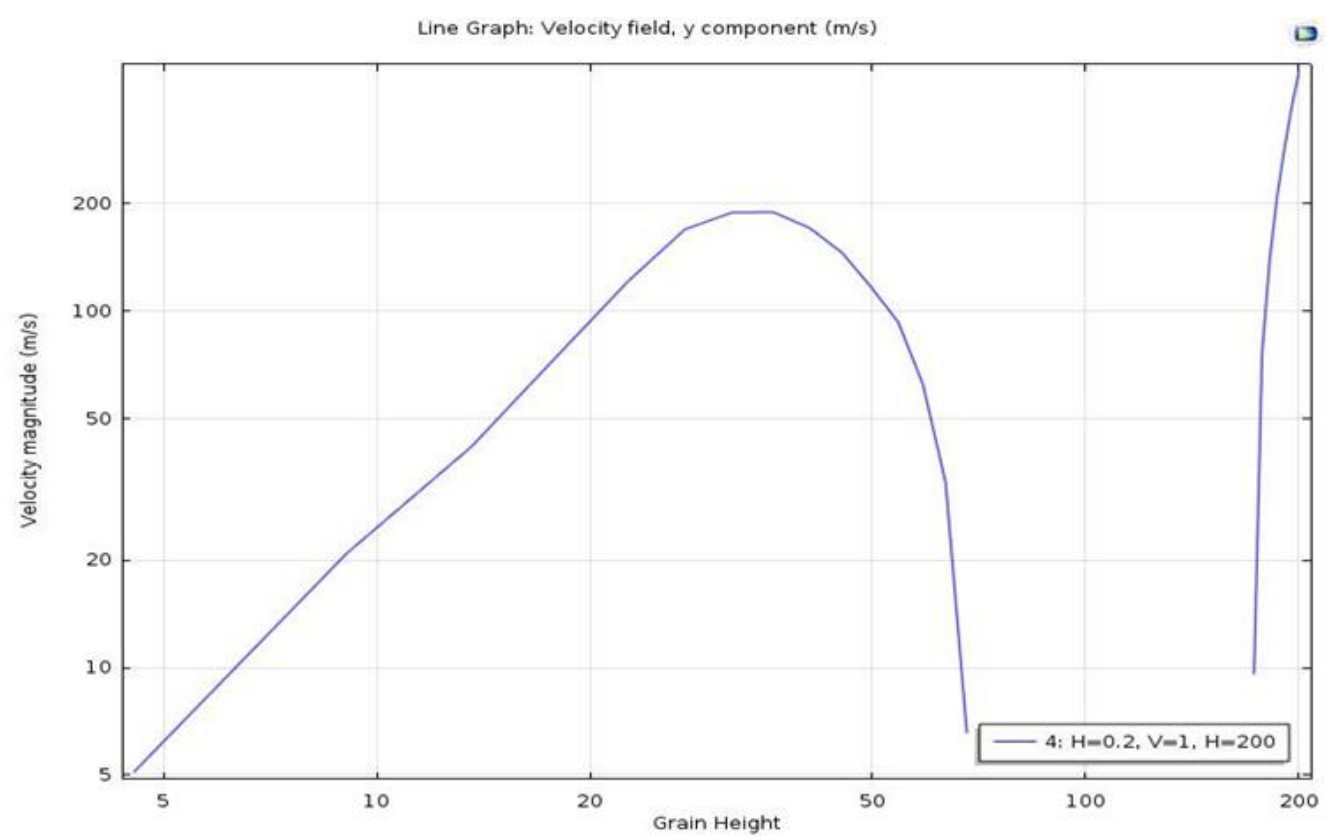

Figure-5. Air Velocity up Single Grain Layer of Height $0.2 \mathrm{~m} \&$ inlet Velocity $1 \mathrm{~m} / \mathrm{s}$. Source: Osodo [29].

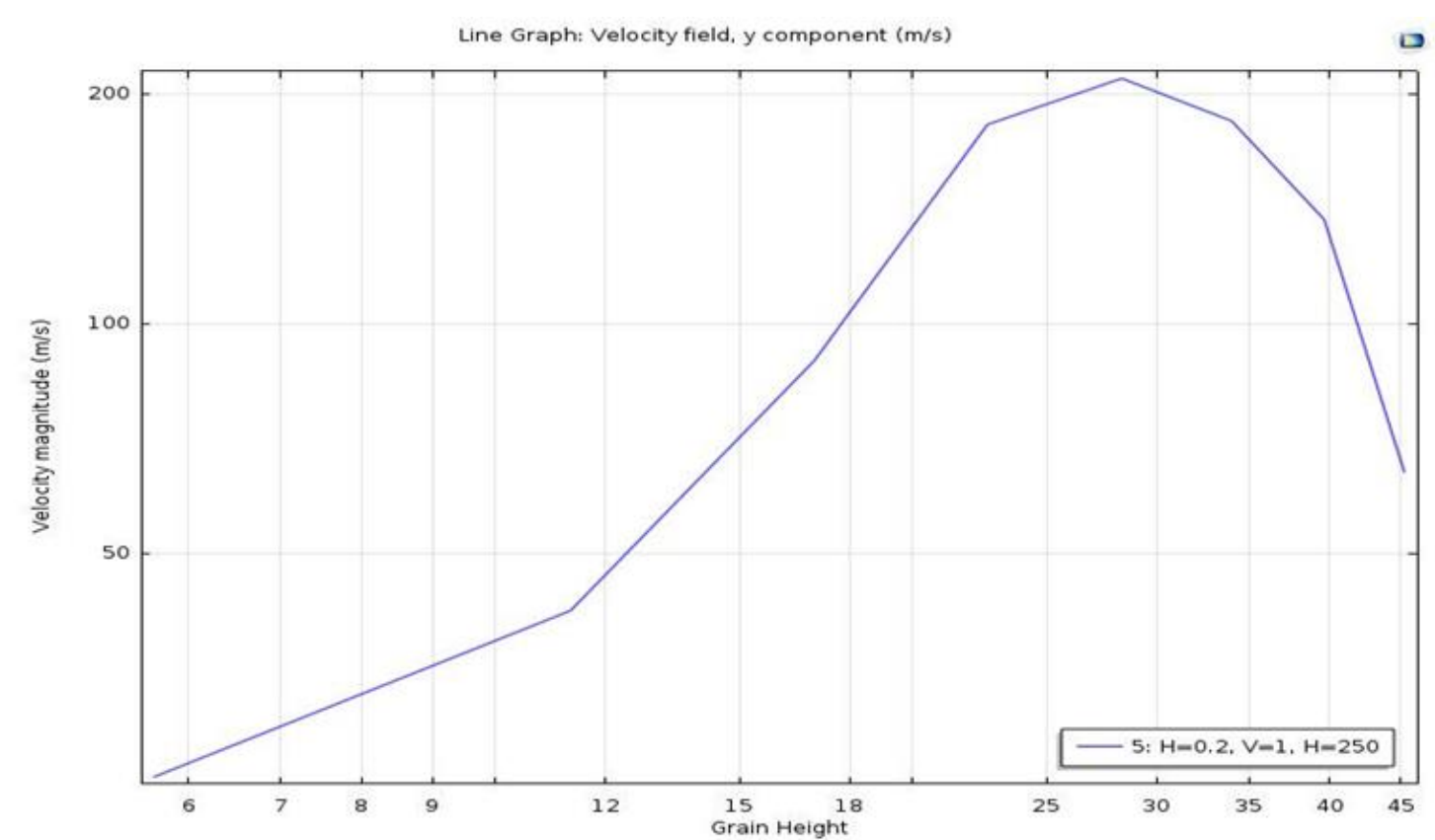

Figure-6. Air Velocity up Single Grain Layer of Height $0.25 \mathrm{~m} \&$ inlet Velocity $1 \mathrm{~m} / \mathrm{s}$. Source: Osodo [29]. 


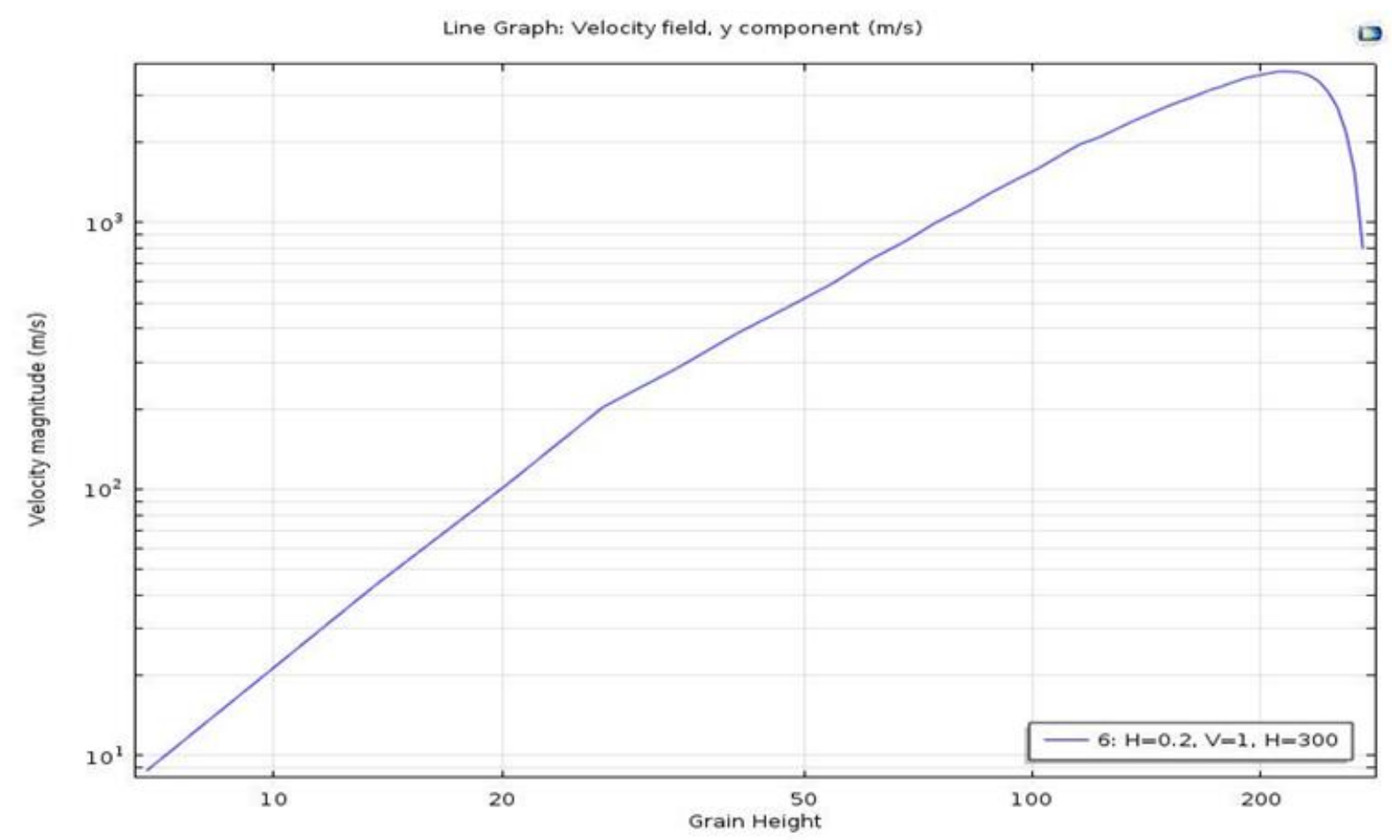

Source: Osodo [29].

Figure-7. Air Velocity up Single Grain Layer of Height $0.3 \mathrm{~m} \&$ inlet Velocity $1 \mathrm{~m} / \mathrm{s}$

It is evident that for grain layer thickness of $0.1 \mathrm{~m}$, air velocity increased gradually up the entire grain layer, leveling off at the top. This was according to expectations. This implied that $0.1 \mathrm{~m}$ would be an appropriate grain layer thickness for this dryer, and that the suction fan would be able to overcome the static pressure i.e. resistance to air flow, in this case. For other layer thicknesses, this was not the case. For example for grain layer thickness of $0.2 \mathrm{~m}$ at inlet velocities $1 \mathrm{~m} / \mathrm{s}$, velocity increased gradually up to a grain layer height of $0.04 \mathrm{~m}$, before falling sharply. Air velocity was again showed to be increasing sharply at the upper sections of the grain layer. The trend at the section at a height between $0.07 \mathrm{~m}-0.18 \mathrm{~m}$ did not show, making it difficult to explain what happened. However, because the expectation was for the air velocity to rise steadily up the grain layer, it was concluded that this was not an appropriate grain layer thickness to use.

For the velocity profile up $0.25 \mathrm{~m}$ grain layer thickness at $1 \mathrm{~m} / \mathrm{s}$, air velocity increased up the grain layer, but only up to a height of $0.03 \mathrm{~m}$ before decreasing, showing again that this was not an appropriate grain layer thickness to use. In the case of a $0.3 \mathrm{~m}$ grain layer thickness, once again air velocity increased up the grain layer, but the increase was not sustained. The velocity dropped way before the top of the grain layer, at a height of about $0.2 \mathrm{~m}$. This showed that this was not an appropriate grain layer thickness to use. Thus it was concluded that the maximum grain layer thickness should be $0.1 \mathrm{~m}$.

\subsection{Number of Layers and Trays}

Pressure profiles for simulated air flow up a drying cabinet with different numbers of grain layers are shown in Figures 8-12.

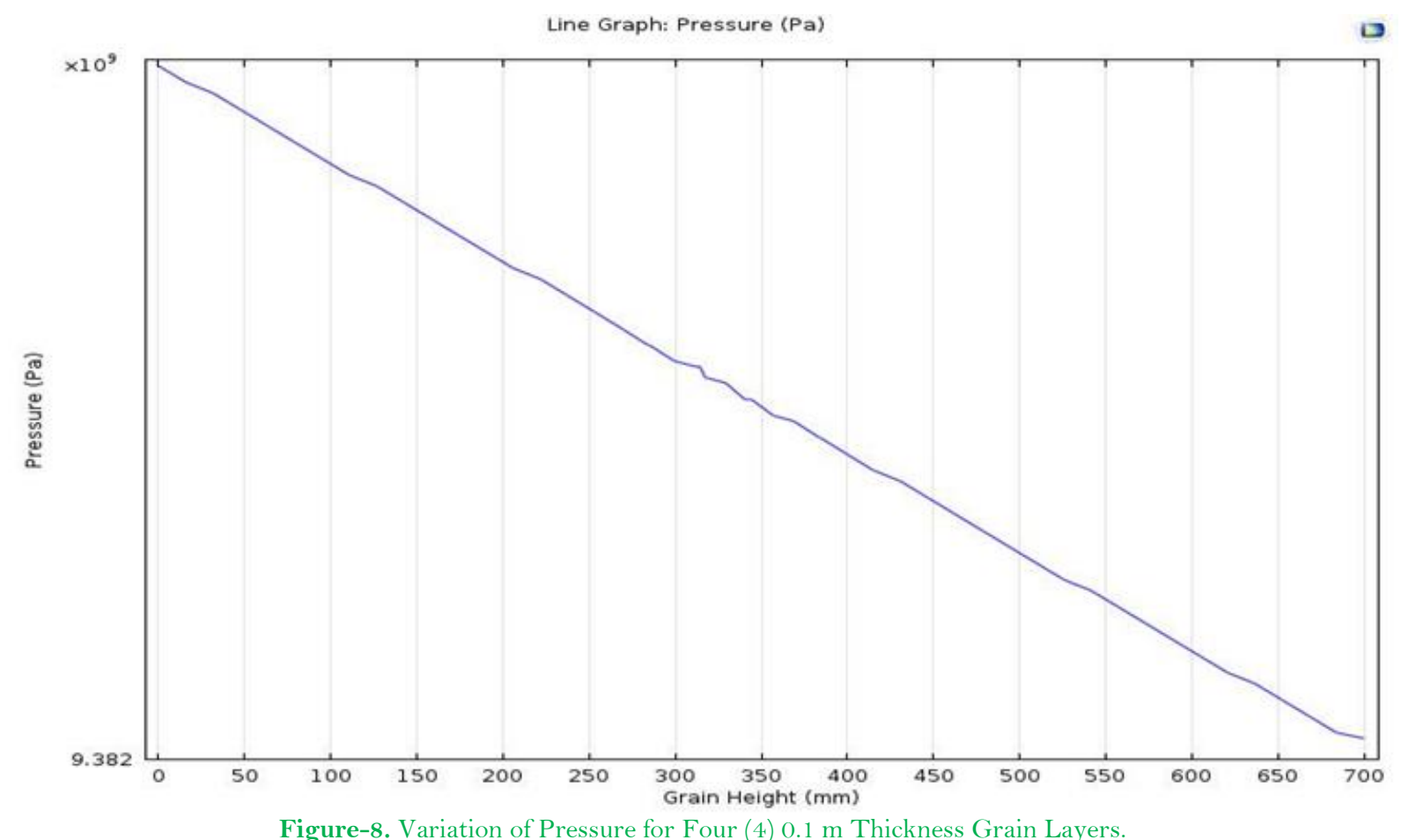

Source: Osodo [29].

Figure-8. Variation of Pressure for Four (4) 0.1 m Thickness Grain Layers. 


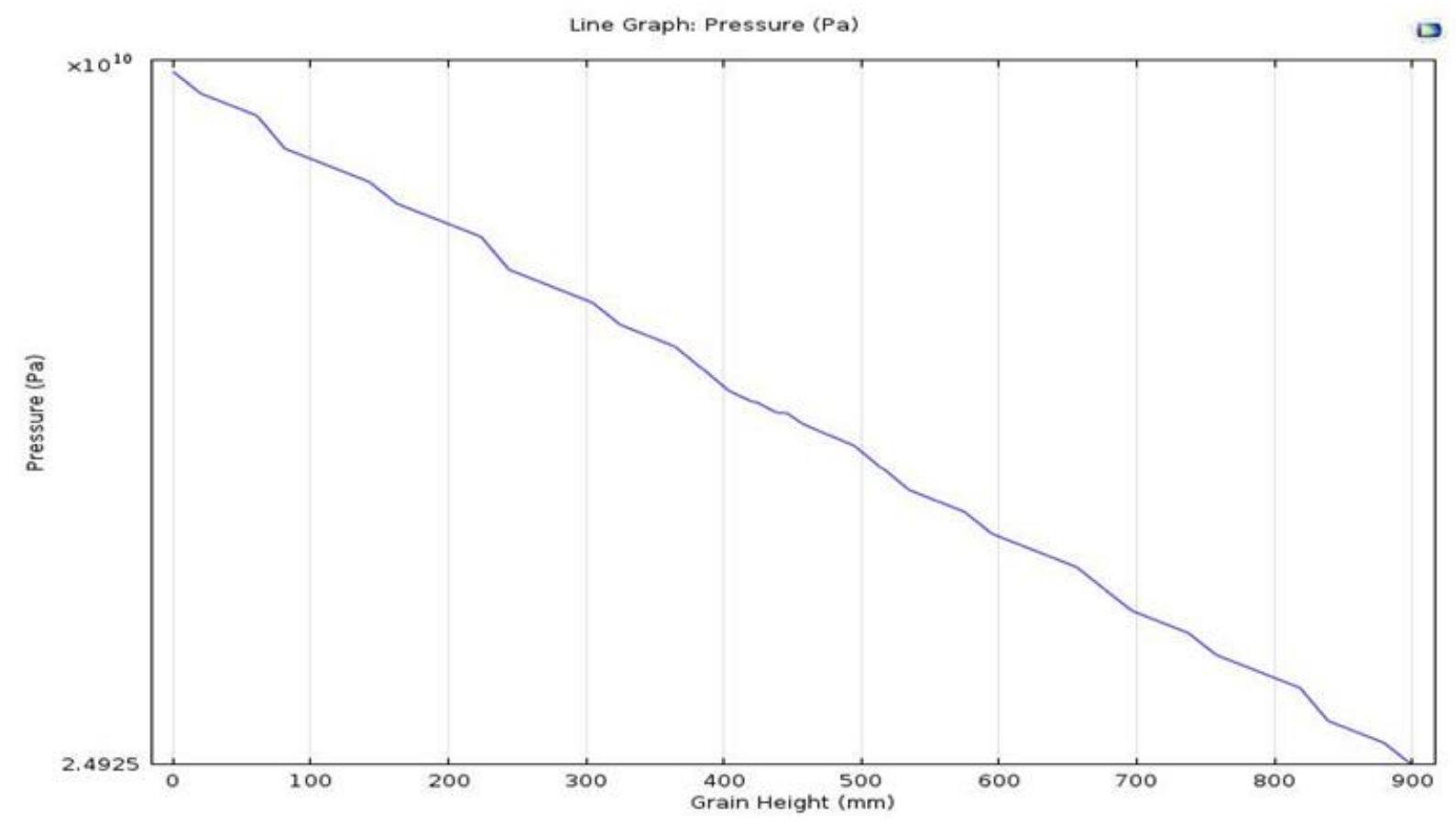

Source: Osodo [29].

Figure-9. Variation of Pressure for Five (5) $0.1 \mathrm{~m}$ Thickness Grain Layers.

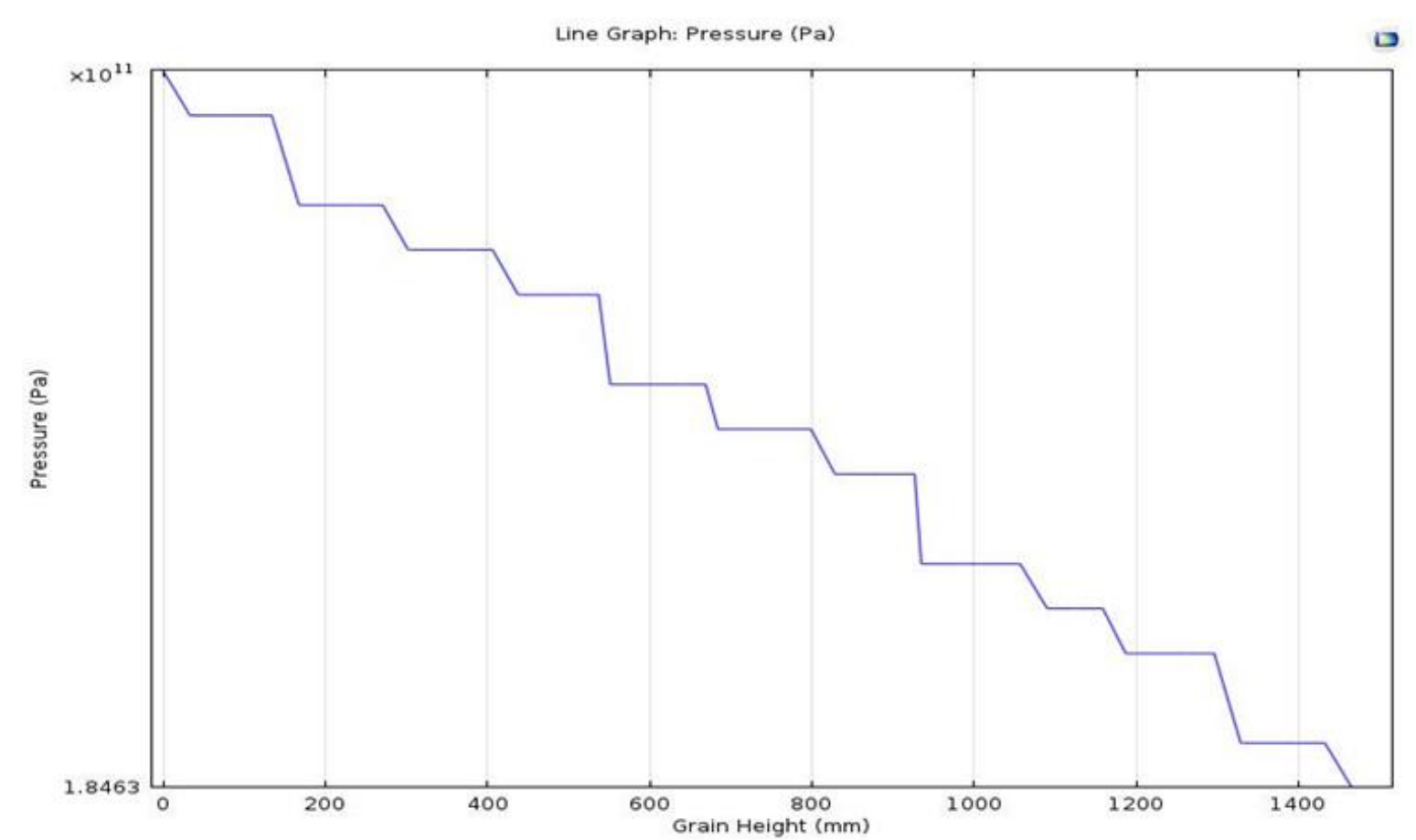

Source: Osodo [29].

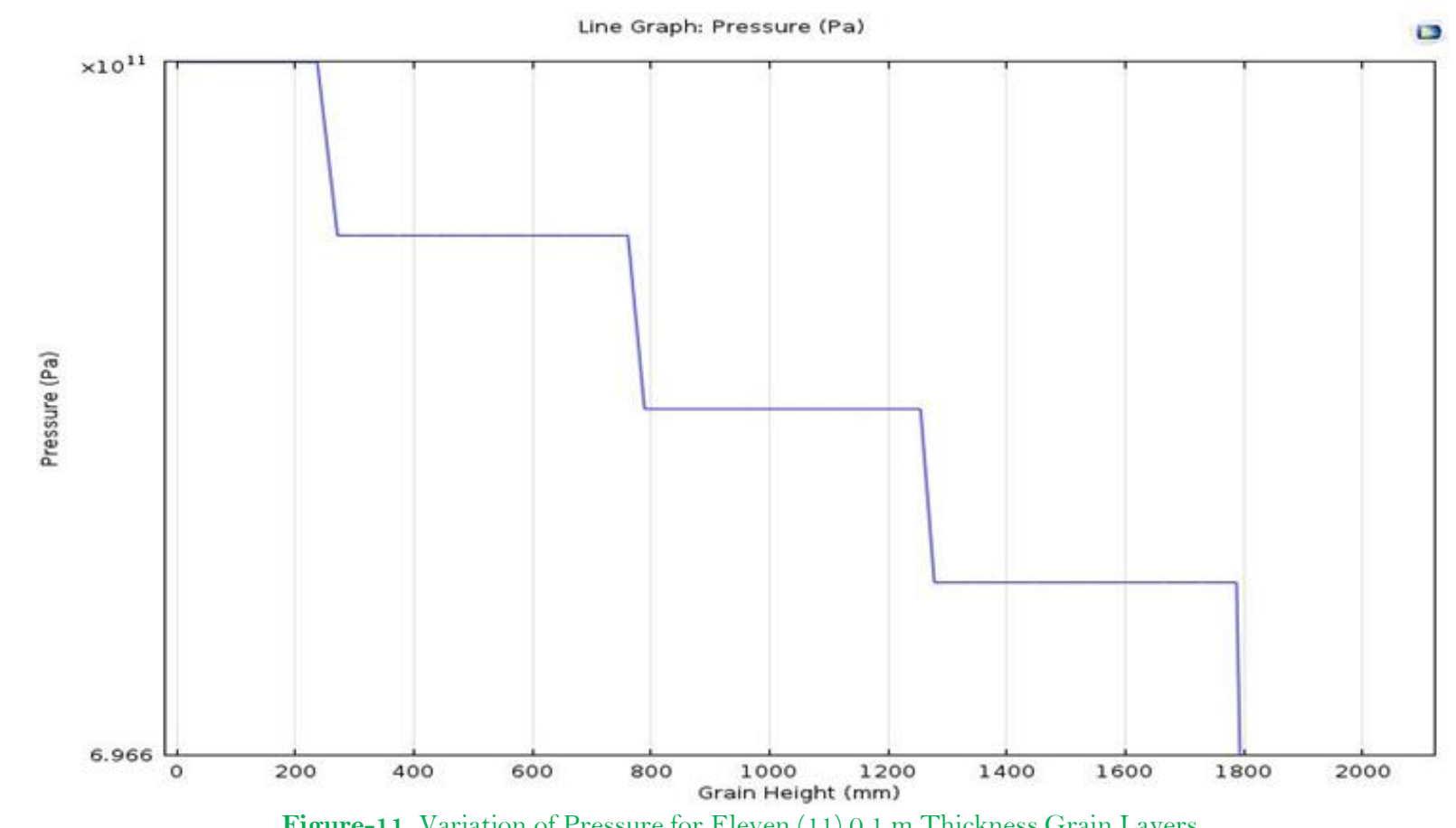

Source: Osodo [29].

igure-11. Variation of Pressure for Eleven (11) 0.1 m Thickness Grain Layers. 


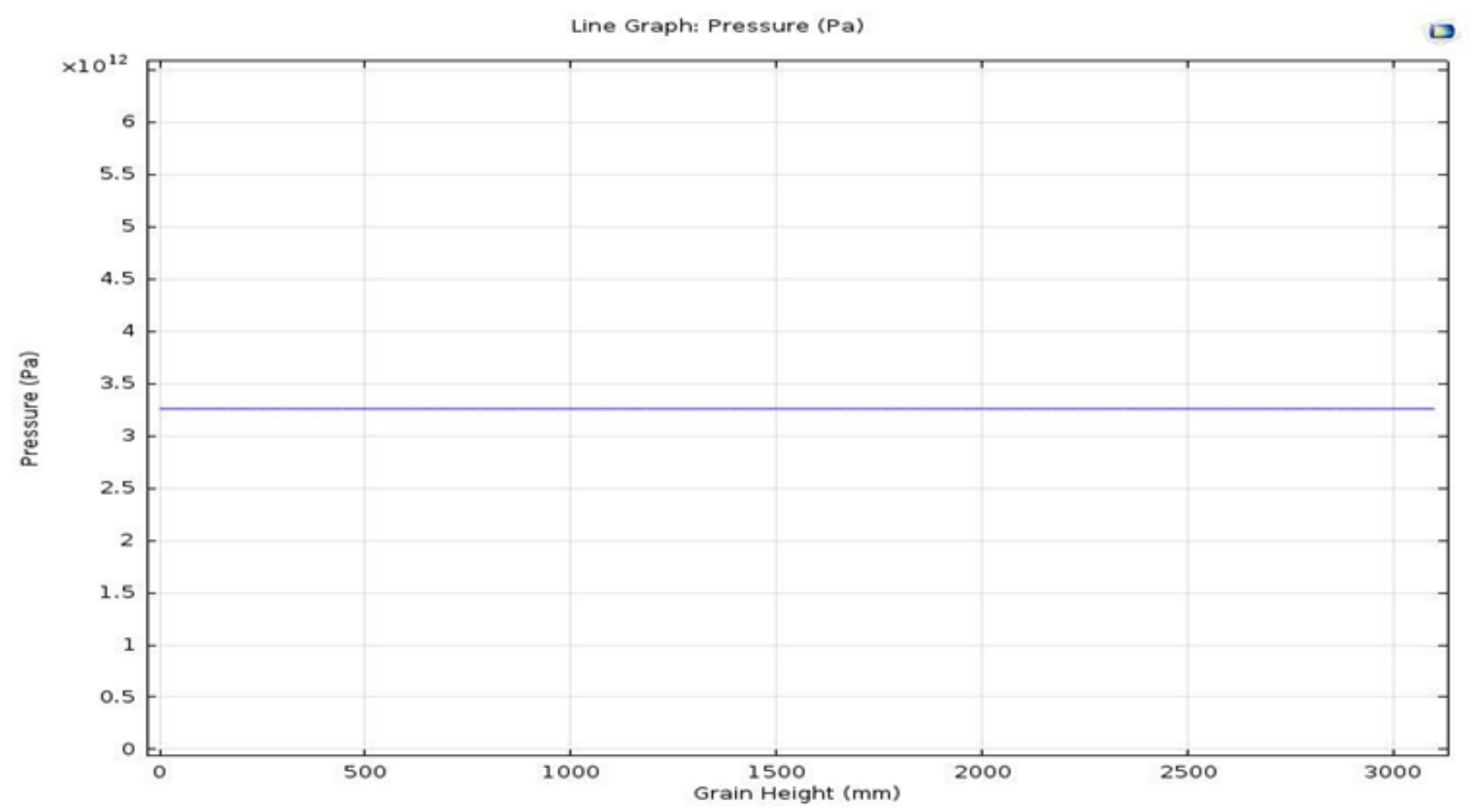

Source: Osodo [29].

Figure-12. Variation of Pressure for Sixteen (16) 0.1 m Thickness Grain Layers.

It was found that beyond four (4) grain layers, the linear trend in pressure drop ceased. From five (5) grain layers and above, there were sections where there was little or no change in pressure, suggesting that there was little or no air flow. Sections where the curve remained horizontal indicated no pressure drop. This trend intensified as number of grain layers increased, with the horizontal sections of the curve becoming longer, indicating no pressure drop for greater distances up the grain layers. This continued to the extent that for sixteen (16) grain layers and beyond, the graph was a horizontal line, showing that there was no pressure drop at all, hence suggesting that no air flow through the grain layers occurred. It was therefore concluded that the grain dryer should be loaded with at most four (4) trays, each with a maximum grain layer thickness of $0.1 \mathrm{~m}$.

\subsection{Sizing of Drying Cabinet and Solar Collector}

Figure 13 shows variation of pressure for simulated air flow up a single $0.1 \mathrm{~m}$ grain layer. It indicates that there was a linear drop in pressure from the lower section of a grain layer upwards.

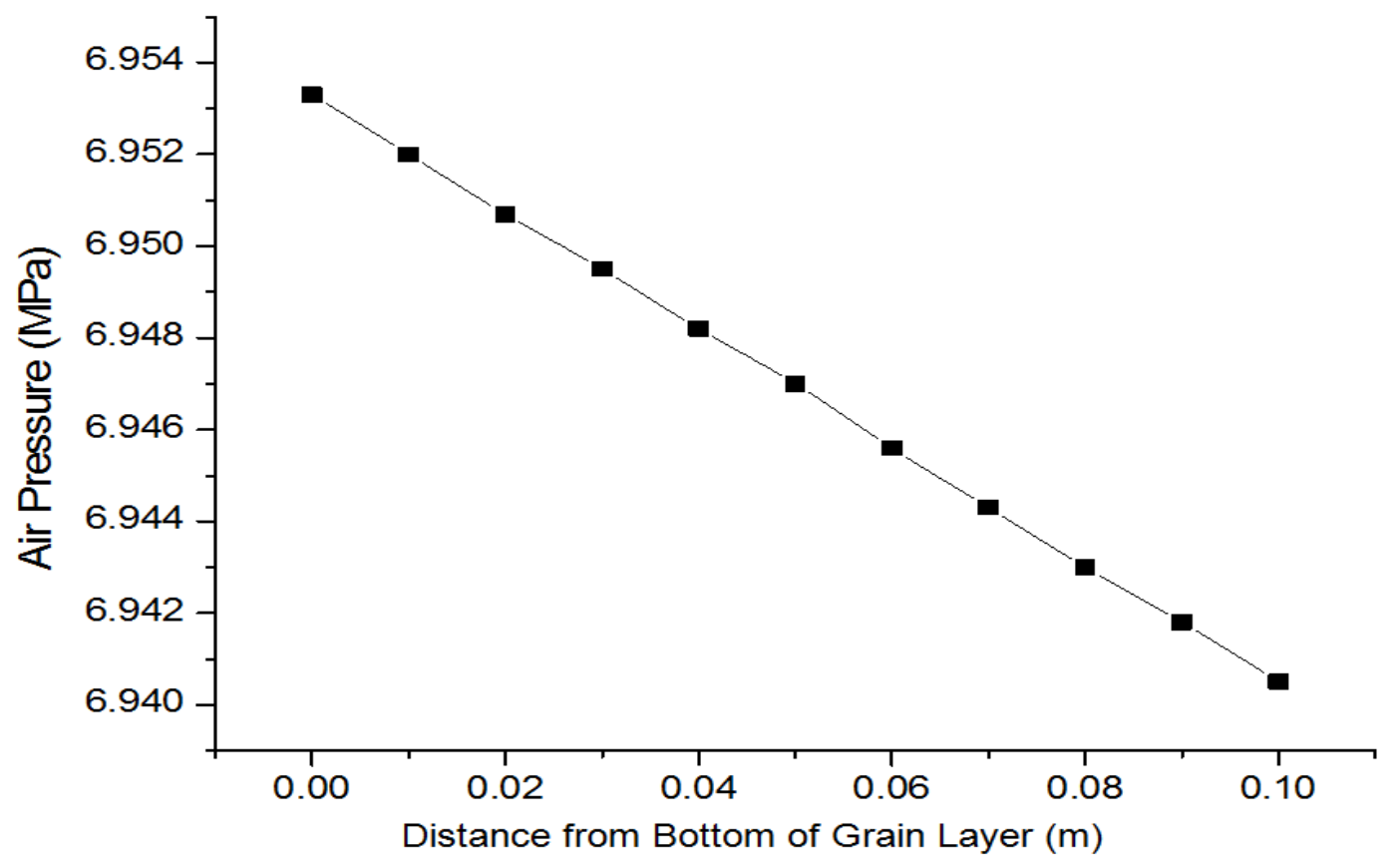

Source: Osodo [29].

Figure-13. Variation of Pressure for a Single Layer of Thickness $0.1 \mathrm{~m}$.

As shown in Figure 13 the total pressure drop for a single $0.1 \mathrm{~m}$ thick layer was $1.28 \times 10^{4} \mathrm{~Pa}$, this being the difference between the highest $(6.9533 \mathrm{MPa})$ and the lowest pressure $(6.9405 \mathrm{MPa})$. For two layers or trays, the total pressure drop would therefore be equal to twice this value. This was due to the assumption that pressure drop would be the same for each layer, since they were of equal thickness. Equation 2 indicates that pressure drop depends on length of bed and void space which were constant. The other variables, namely particle size, fluid viscosity and density were also assumed to be constant. This yielded a total pressure drop of $2.56 \times 10^{4} \mathrm{~Pa}$ for two (2) grain layers, which was found to be equivalent to a static pressure $P_{S}$ of 102.8 inches of water. Using Equation $5-8$ the air volume flow rate $V_{S}$ was determined to be $1.984 \mathrm{cfm}$. By applying Equation 4 the fan power $P_{f}$ was found to be $0.053 \mathrm{Hp}(0.039 \mathrm{~kW})$. 


\subsubsection{Drying Cabinet Sizing}

Although it was found that maximum number of trays should be four, the experimental dryer was designed to carry two trays. Each drying tray with a capacity of $18 \mathrm{~kg}$ was sized to be of square cross section $0.5 \mathrm{~m} \mathrm{x} 0.5 \mathrm{~m}$. using Equation 5 and 6. The lowest tray was to be placed $0.3 \mathrm{~m}$ from the bottom to allow for the plenum chamber, and the second one $0.2 \mathrm{~m}$ above (0.1 m each for grain layer and void space). Leaving $0.3 \mathrm{~m}$ above the upper tray for fitting the fan, this resulted in a total drying cabinet height of $1 \mathrm{~m}$.

\subsubsection{Solar Collector Sizing}

Using an air velocity, $\mathrm{v}$ of $0.3 \mathrm{~m} / \mathrm{s}$ (the lowest recommended for drying of grains) and drying cabinet cross section $0.25 \mathrm{~m}^{2}$, the volume flow rate $Q$, through the collector was determined to be $0.075 \mathrm{~m}^{3} / \mathrm{s}$ (mass flow rate $\dot{m}$ $=0.092 \mathrm{~kg} / \mathrm{s}$ ), using Equation 7 and 8 . Assuming a maximum temperature $\mathrm{T}_{\mathrm{o}}$ of $58^{\circ} \mathrm{C}$ (to maintain grain quality), and an ambient temperature $\mathrm{T}_{\mathrm{i}}$ of $23^{\circ} \mathrm{C}$ (measured in research area during drying period) as well as an insolation $\mathrm{I}_{\mathrm{c}}$ of $1200 \mathrm{~W} / \mathrm{m}^{2}$, the required solar collector area was determined to be $3.25 \mathrm{~m}^{2}$ after applying Equation 1 . A solar collector efficiency $\eta$ of $83.28 \%$, as achieved by Aduewa, et al. [19] at an insolation of $1199.46 \mathrm{~W} / \mathrm{m}^{2}$ was used in the determination.

\section{Conclusions}

As a result of this study, an experimental grain dryer shown in Figures 4-6 and Plates 1 and 2 was sized and fabricated. Simulation led to the conclusion that the grain dryer should be loaded with at most four (4) trays, each with a maximum grain layer thickness of 0.1 . Having decided to design a dryer with two drying trays, a drying cabinet of dimensions $0.5 \mathrm{~m} \times 0.5 \mathrm{~m} \times 1.0 \mathrm{~m}$ was adopted. It was designed to be equipped with a $0.039 \mathrm{~kW}$ centrifugal fan. The solar air heater was designed to have a collector area of $3.25 \mathrm{~m}^{2}$.

\section{References}

[1] A. B. Adebayo, G. Ndunguru, P. Mamiro, B. Alenkhe, N. Mlingi, and M. Bekunda, "Post-harvest food losses in a maize-based farming system of semi-arid savannah area of Tanzania," Journal of Stored Products Research, vol. 57, pp. 49-57, 2014. Available at: https://doi.org/10.1016/j.jspr.2013.12.004.

[2] C. Bett and R. Nguyo, "Post-harvest storage practices and techniques used by farmers in semi-arid Eastern and Central Kenya," in African Crop Science Conference Proceedings, 2007, pp. 1023-1222.

[3] B. O. Bolaji and A. P. Olalusi, "Performance evaluation of a mixed mode solar dryer," AU Journal of Technology, vol. 11 , pp. 225-231, 2008.

[4] J. Irungu, "Post harvest challenges to food security in Kenya," presented at the A paper presented at KCB Leadership Center, Karen, Nairobi, 2010.

[5] R. Hodges, Supplying cereal grain postharvest losses information: The examples of ALPHIS (African postharvest Loss information system). UK: Natural Resources Institute, 2009.

[6] G. N. Tiwari, Solar energy: Fundamentals, design, modeling and applications. Parybourne: Alpha Science International Limited, 2002.

J. W. Twidell and A. D. Weir, Renewable energy resources. London: English Language Book Society, 2006.

P. Barawal and G. N. Tiwari, "Grape drying by using photovoltaic thermal (PV/T) green house dryer: An experimental study of solar energy," Solar Energy, vol. 62, pp. 1131-1144, 2008.

[9] O. A. Akinona, A. A. Akinyemi, and B. O. Bolaji, "Evaluation of traditional and solar fish drying systems towards enhancing fish storage and preservation in Nigeria," Fish International: Pakistan, vol. 1, pp. 44-49, 2006.

[10] D. G. Mercer, "A comparison of the kinetics of Mango drying in open-air, solar and forced air dryers," African Journal of Food, Agriculture, Nutrition and Development, vol. 12, pp. 6835-6852, 2012.

[11] Y. I. Sallam, M. H. Aly, A. F. Nassar, and E. A. Mohamed, "Solar drying of whole mint plant under natural and forced convection," Journal of Advanced Research, vol. 6, pp. 171-178, 2013. Available at: https://doi.org/10.1016/j.jare.2013.12.001.

[12] M. Mohanraj and P. Chandrasekar, "Performance of a forced convection solar drier integrated with gravel as heat storage material for chili drying," Journal of Engineering Science and Technology, vol. 4, pp. 305-314, 2009.

[13] A. Kassem, M. A. Al-Sulaiman, A. Aboukarima, and S. Kassem, "Predicting drying efficiency during solar drying process of grapes clusters in a box dryer using artificial neural network," Austratian Journal of Basic and Applied Sciences, vol. 5, pp. 230-241, 2011.

[14] J. K. Afriyie, H. Rajakaruna, M. A. Nazha, and F. Forson, "Simulation and optimisation of the ventilation in a chimney-dependent solar crop dryer," Solar Energy, vol. 85, pp. 1560-1573, 2011. Available at: https://doi.org/10.1016/j.solener.2011.04.019.

[15] S. Misha, S. Mat, M. A. M. Rosli, M. H. Ruslan, K. Sopian, and E. Salleh, "Simulation of air flow in a tray dryer by CFD," Recent Advances in Renewable Energy Sources, vol. 1, pp. 29-34, 2013.

[16] C. A. Frangopoulos, M. R. Von Spakovsky, and E. Sciubba, "A brief review of methods for the design and synthesis optimization of energy systems," International Journal of Applied Thermodynamics, vol. 5, pp. 151-160, 2002.

[17] J. Klaus, I. Olindo, H. M. S. Amo, A. C. Rene, and Z. Miro, "Solar energy: Fundamentals, technology and Systems," Delft University of Technology, 2014.

[18] V. Dabra, L. Yadav, and A. Yadav, "The effect of tilt angle on the performance of evacuated tube solar air collector: experimental analysis," International Journal of Engineering, Science and Technology, vol. 5, pp. 100-110, 2013. Available at: https://doi.org/10.4314/ijest.v5i4.9.

[19] T. O. Aduewa, A. S. Ogunlowo, and S. T. Ojo, "Development of hot air supplemented solar dryer for white yam (Dioscorea Rutundata) slices," IOSR Journal Of Agricultural And Veterinary Services, vol. 7, pp. 114-123, 2014. Available at: https://doi.org/10.9790/2380-07122114123.

[20] Y. Jia, Y. Li, and D. Hlavka, "Flow through packed beds." Available: http:/ www.me.rochester.edu/courses/ME241/11-sand.pdf. [Accessed 14th September 2014], 2009.

[21] S. Sachdeva, S. Pareek, B. Mahadevan, and A. Deshapande, "Modeling and simulation of single phase fluid flow and heat transfer in packed bed," in Proceedings of 2012 COMSOL Conference, Bangalore, 2012.

[22] W. Aissa, M. El-Sallak, and A. Elhakem, "Performance of solar dryer chamber used for convective drying of spongecotton," Thermal Science, vol. 18, pp. 451-462, 2014. Available at: https://doi.org/10.2298/tsci1 10710084a.

[23] W. F. Wilcke and R. V. Morey, "Selecting fans and determining airflow for crop drying, cooling and storage. Available: http://www.extension.umn.edu/agriculture/crops. [Accessed 15th September 2015], 2015. 
[24] D. E. Maier and F. W. Bakker-Arkema, "Grain drying systems," in Paper Presented at Facility Design Conference of Grain Elevator and Processing Society held on July 28-31 in St Charles, Illinois, USA, 2002.

[25] W. Weiss and J. Buchinger, Solar drying. Training course within the scope of the project establishment of a production, sales and consulting infrastructure for solar thermal plants in Zimbabwe. Australia: Australian Development Cooperation, Institute of Sustainable Technologies, 2012.

[26] L. M. Omwando, "Assessment of solar energy potential for Nakuru, Kenya," Unpublished Masters Thesis, Jomo Kenyatta University of Agriculture \& Technology, Kenya, 2012.

[27] D. Walubengo, "Community-led actions in building resilience to climate change: A Kenya case study. Retrieved from pubs.iied.org/pdfs/go2310pdf . [Accessed 30th November 2015]," 2007.

[28] H. Maloba, W. Shivonga, M. Muchiri, and S. N. Miller, "Use of benthic macro-invertebrates as indicators of water quality in Njoro River, Kenya," in Proceedings of TAAL 2007: the 12th World Lake Conference, 2008, pp. 2161-2168.

[29] B. O. Osodo, "Simulation and optimisation of a drying model for a forced convection grain dryer." Unpublished PhD Thesis, Kenyatta University, Kenya, 2018. 